\title{
Standardization of recipe for the preparation of low calorie RTS beverage from pineapple (Ananas comosus) using sugar substitutes
}

\author{
B. Mansoor*, A.R. Sawate, B.M. Patil and R.B. Kshirsagar \\ Department of Food Engineering College of Food Technology, Vasantrao Naik Marathwada Krishi Vidyapeeth, PARBHANI \\ (M.S.) INDIA \\ Email : mansoor.f.tech@gmail.com

SUMMARY :

The investigation on standardization of recipe for preparation of low clorie RTS beverage from pineapple (Ananas comosus) using sugar substitutes was conducted. The experiment was laid out in Factorial Completely Randomized Design with aspartame, sucralose and their combination with cane sugar (sucrose) with 15 per cent juice and 0.3 per cent acidity. The RTS beverage with sucrose was the control. Sugar substitutes were used in place of sugar based on sugar equivalents. The prepared RTS beverages were analysed for chemical composition and sensory quality attributes. Among different combination sugar substitutes, sample D prepared by using $50 \%$ sucrose $+50 \%$ sucralose was reached with highest sensory scores for overall acceptability.

KEY WORDS : Pineapple, Chemical analysis, Low calorie sweeteners, RTS beverage

How to cite this paper : Mansoor, B., Sawate, A.R., Patil, B.M. and Kshirsagar, R.B. (2016). Standardization of recipe for the preparation of low calorie RTS beverage from pineapple (Ananas comosus) using sugar substitutes. Internat. J. Proc. \& Post Harvest Technol., 7 (2) : 243-247. DOI: 10.15740/HAS/IJPPHT/7.2/ 243-247. 